\title{
An Investigation to reduce emissions from IC Engines
}

\author{
P K Pavan Kumar ${ }^{1}$, Dr. K. Rajagopal ${ }^{2}$, Dr. Hiregoudara Yerrennagoudaru ${ }^{3}$, \\ Kalburgi Bharath ${ }^{4}$ \\ 1,3,4(Mechanical Engg. Department, RYMEC/VTU, INDIA) \\ 2(VC, S.K.University, Ananthapuramu, INDIA)
}

\begin{abstract}
The combustion process of fuel in the internal combustion engine produces exhaust gases at the end of each cycle. The exhaust gases compose of harmful emissions like CO, HC and NOx. The emissions concentration depends on the number of varying parameters of the combustion of fuel in the internal combustion engine. The exhaust gases cause to the pollution of atmosphere which is a problem every nation is suffering to the effects caused by emissions from the automobiles, either from two stroke engines or from engines operating at four stroke, either diesel or gasoline engine. Therefore, the need of the hour is to reduce the harmful emissions from the exhaust gases by exposing the exhaust gases to react with the catalyst and reduce the concentration of the emissions. Conventional systems and methods are attempted to reduce this problem by using three way catalytic converters which uses catalysts to react with the gases and reduce emissions from the exhaust gases. The presented work is been developed to provide an alternate way of addressing the problems which are not yet fully answered by conventional methods in a cost effective manner. Hence we have designed an exhaust pipe which is been coated with aluminium silicate, sodium silicate and activated charcoal which replaces the conventional exhaust pipe in a two stroke petrol engine. The exhaust gases from the outlet valve of the engine are at sufficient temperatures to react with the coating in the exhaust pipe. Emissions like $\mathrm{CO}$ and $\mathrm{HC}$ are checked from the exhaust gases using the developed exhaust pipe on a two stroke petrol engine. The goal of the project is to develop a specific knowledge as to whether this method will reduce the emissions from the exhaust gases.
\end{abstract}

Keywords: Activated charcoal, Aluminium silicate, Emissions, Exhaust pipe, Sodium silicate.

\section{Introduction}

At present every nation is suffering to the effects caused by emission from the automobiles either from two stroke engines or from engines operating with four stroke, either diesel or gasoline engine. The emissions like Hydrocarbon (HC), Carbon Monoxide (CO), Nitrogen oxide (NOx) are hazardous to human beings and cause atmospheric pollution. With thousands of automobiles manufactured and purchased daily, the pollution level increases by the emissions from the vehicles there is always a danger of smog formation [1]. It is necessary to reduce the emissions from the automobiles till we can find alternate fuel for the present existing engines which gives less emission. The emissions which are undesirable for the atmosphere from the automobiles are studied extensively in the recent decades to ensure that the pollution of the atmosphere does not exceed the limit for human breathing. Also various methods are also in practice to reduce the emissions for all types of engines and stringent rules are being followed for the norms of emissions for the engine day by day [2]. In order to reduce the emissions from the exhaust gases from the automobiles, conventional methods are present [3], which are not so economic. Instead of using conventional catalytic converter which is expensive, we have tried to reduce the emissions by fabricating a new exhaust pipe coated with aluminium silicate and activated charcoal and have studied the emissions and compared the result with the conventional exhaust pipe. The exhaust pipe is fitted with a baffle so that the exhaust gases from the engine are exposed to the refractory coating which is coated on the baffle as well as the inner surface of the exhaust pipe which will help to reduce the emissions of the exhaust. We know that the emissions from the present automobiles are as per the emission norms stipulated, but still there is a need to reduce these emissions which are undesirable. The exhaust gases coming out from the outlet valve of the engine are exposed at sufficient temperature that they can react with the refractory coating which reduces the hydrocarbon and carbon monoxide in the exhaust pipe. We are using here aluminium silicate and activated charcoal as for reducing the emissions by fitting the developed exhaust pipe to two stroke petrol engine by replacing its original exhaust pipe. Aluminium silicate is a fibrous material which consists of aluminium oxide and silicon dioxide, it is a glassy solution. The temperature resistance increases as the alumina content increases and it is used as a refractory in ceramic industry. Magnesium aluminium silicate when hydrated becomes a clay known as kaolin, and is used for treating ailments like diarrhea and diaper rash and also rashes from poison oak and poison ivy. It is also used in antacids and also as thickener in cosmetics and beauty products [4]. Activated charcoal is a carbon form which is processed to have low volume which increases the surface area for adsorption and chemical reaction. Major applications of activated charcoal are its 
use in metal finishing yield, purification technique for removal of organic impurities, medical uses for poisoning and overdoses, many applications in removal of pollutants from air and water stream. It is also used for gas purification which removes oil vapors and hydrocarbons from gas [5]. Sodium silicate also known as waterglass or liquid glass, it is available in aqueous solution and in solid form. The pure compositions are colorless or white, but commercial samples are often greenish or blue owing to the presence of iron-containing impurities. It is used as adhesive, used in refractory and also used for automotive repairs [6]. Different chemical compounds can be used in various design of exhaust pipe to reduce the emissions from the exhaust gases by the works carried out in this regard. Work on an exhaust pipe coated with refractory and activated carbon is carried out and emission tests on the two stroke engine are carried out, results showed that the composition of $20 \%$ activated carbon and $80 \%$ refractory reduced the $\mathrm{CO}$ and $\mathrm{HC}$ emissions considerably [7]. Another work carried out to reduce the emissions followed to study elements which produced reactions similar to the catalytic converter and Zirconium dioxide and Copper nitrate are chosen. Zirconium dioxide is coated to ceramic filter candel and Copper nitrate is pasted to nets and placed in exhaust pipe. The results showed that the CO emissions were reduced by $62.5 \%$ and $\mathrm{HC}$ emissions reduced by $57.4 \%$ comparing before installation of the setup [8]. Charcoal-oil silencer work was carried out to reduce emissions on four stroke petrol engine which had modified silencer having granular charcoal and oil in the silencer. The emission tests showed that the CO and HC emission reduced for the entire range of speed from idling to $60 \mathrm{kmph}$ [9]. Another work to reduce pollutant emission from two wheeler automobiles using nano-particles as catalyst is carried out, Copper nano particles are used as a catalyst and a catalytic converter type is made by nano copper particles and exhaust gases are passed through this catalytic bed. Results showed that the emissions were reduced with this converter [10]. These methods are not only economic, but also provides us a spectrum of opportunities to carry out more work on this idea.

\section{Experimental Setup}

The experiment is carried out on two stroke engine by replacing the original exhaust pipe with the newly fabricated exhaust pipe by us. The new exhaust pipe is made up of steel and is constructed by machining processes and joining processes in the workshop. The exhaust pipe is also fitted with a baffle inside the exhaust pipe which is also made up of steel. The internal surface of the exhaust pipe and the baffle is coated with the refractory containing aluminium silicate and activated charcoal.

Aluminium silicate and sodium silicate together and activated carbon are mixed in the ratio $4: 1$ by weight; moisture may be added while mixing if needed. Care should be taken that no foreign particles are mixed in the refractory slurry while mixing. The exhaust pipe is coated manually with the refractory on inner surface of exhaust pipe and baffle uniformly up to $2 \mathrm{~mm}$ and the coating is warmed up by passing hot gases to flow through the pipe to remove excess moisture content. The fabricated exhaust pipe is thus fixed to the two stroke petrol engine and emission tests are carried out.

\section{Tables}

\begin{tabular}{|c|c|c|c|c|}
\hline & $\begin{array}{c}\text { Prescribed } \\
\text { level CO }(\%)\end{array}$ & $\begin{array}{c}\text { Measured } \\
\text { standard CO }(\%)\end{array}$ & $\begin{array}{c}\text { Prescribed level } \\
\text { HC(PPM) }\end{array}$ & $\begin{array}{c}\text { Measured standard } \\
\text { HC(PPM) }\end{array}$ \\
\hline Conventional exhaust pipe & 3.5 & 2.377 & 6000 & 566 \\
\hline Only refractory coated exhaust pipe & 3.5 & 1.675 & 6000 & 600 \\
\hline Refractory coated with $20 \%$ ACF without baffles & 3.5 & 0.814 & 6000 & 504 \\
\hline Refractory coated with $30 \%$ ACF without baffles & 3.5 & 0.589 & 6000 & 691 \\
\hline Refractory coated with $40 \%$ ACF without baffles & 3.5 & 0.424 & 6000 & 592 \\
\hline Refractory coated with $20 \%$ ACF with baffles & 3.5 & 1.056 & 6000 & 188 \\
\hline
\end{tabular}

Table-1 Observed readings of CO \& HC emissions for different arrangements of exhaust pipe.

\section{Objective}

Objective of the present study is to:

1. Reduce emissions like $\mathrm{HC}$ and $\mathrm{CO}$ in the exhaust gases by the fabricated exhaust pipe.

2. To analyze the emissions by measure the emissions in the exhaust gases.

3. To reduce temperature of the exhaust gases.

4. To conduct emission test on two stroke petrol engines and study results. 


\section{EMISSION GRAPHS}

\section{Results}

\subsection{Unburnt Hydro Carbon}

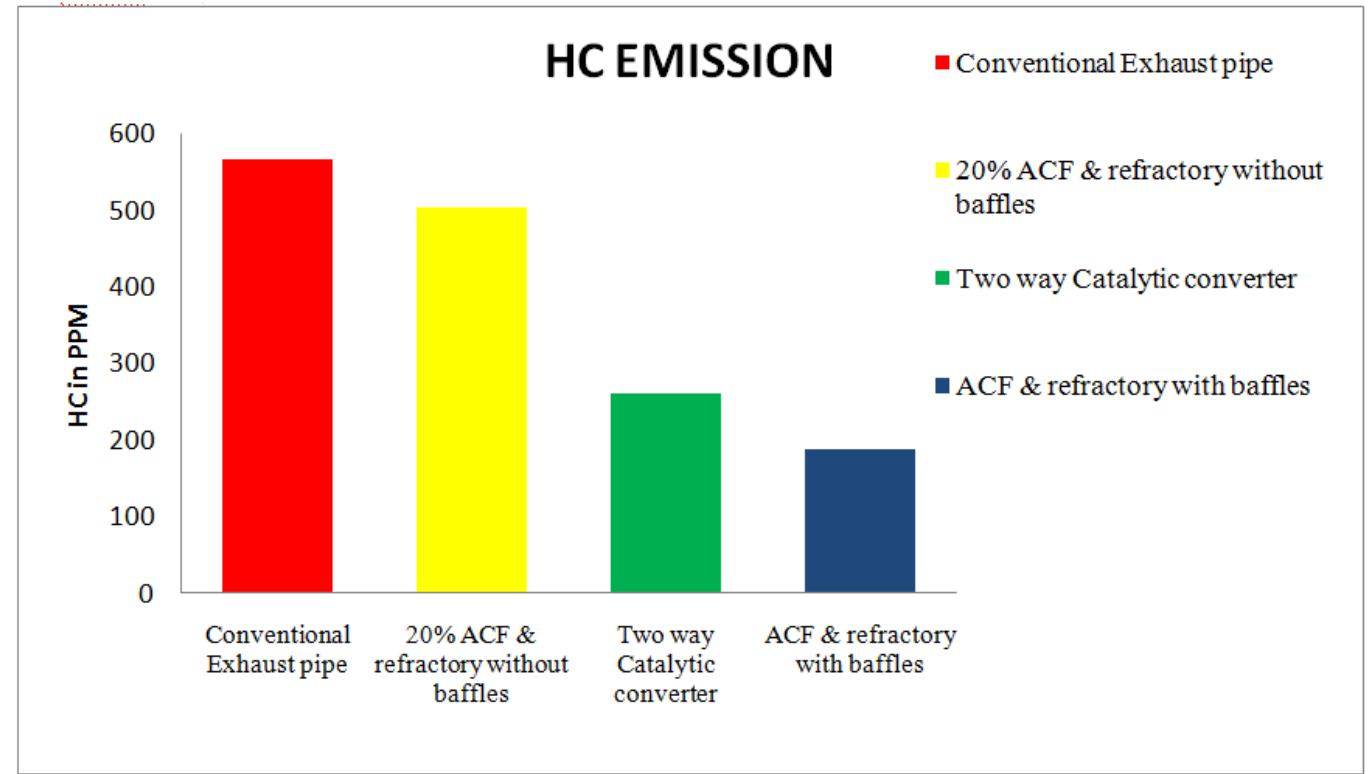

Fig-1 Shows the variation for different arrangements of the exhaust pipe on HC emissions of two stroke petrol engine. It is understood that, the exhaust pipe coated with $20 \%$ activated carbon and refractory with baffles shows least HC emissions. When compared with the conventional exhaust pipe $66 \%$ of $\mathrm{HC}$ emissions are reduced due to the chemical adsorption of $\mathrm{HC}$ by the activated carbon. The chemical reaction oxidizes the hydrocarbon to carbon dioxide and water. There is also importance for the baffles as there is more surface area for adsorption of HC.

Oxidation of hydrocarbons (unburned and partially burned fuel) to carbon dioxide and water:

$\mathrm{CXH2X}+2+[(3 \mathrm{X}+1) / 2] \mathrm{O} \square \mathrm{XCO2}+(\mathrm{X}+1) \mathrm{H} 2 \mathrm{O}$

\subsection{Carbon Monoxide}

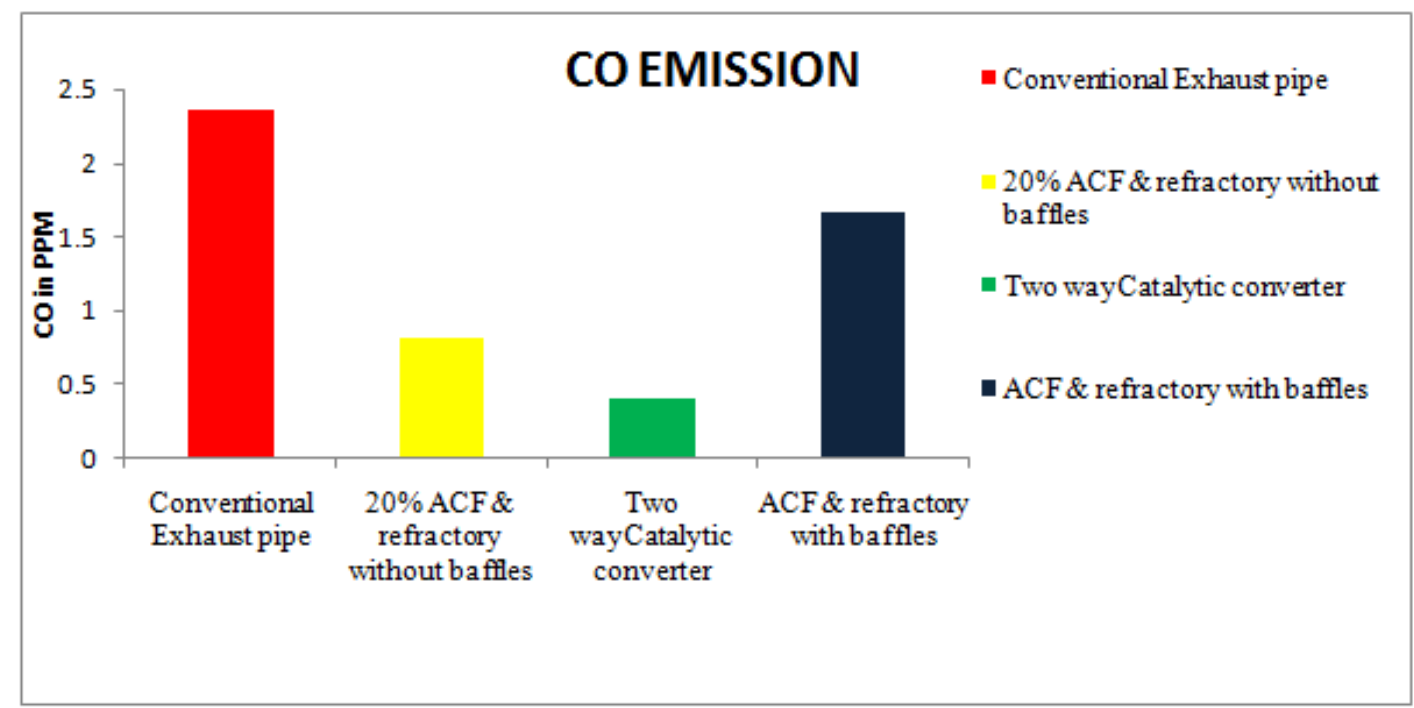

Fig-2 Shows the variations for different arrangements of the exhaust pipe on $\mathrm{CO}$ emissions of two stroke petrol engine. It is understood that two way catalytic converter shows least $\mathrm{CO}$ emissions. The exhaust pipe coated with $20 \%$ activated carbon and refractory without baffles has the second least emission of CO. When compared with the conventional exhaust pipe 55\% of $\mathrm{HC}$ emissions are reduced due to the chemical reaction and oxidation of carbon monoxide to carbon dioxide.

Chemical reaction of Oxidation of carbon monoxide to carbon dioxide: $\mathbf{2 C O}+\mathbf{O 2} \square \mathbf{2 C O}$ 


\section{Conclusion}

From the experiment, it is observed that there is a considerable reduction in harmful emissions like HC and $\mathrm{CO}$ by using this method of coating the exhaust pipe with these materials. The graph shows that there is a reduction of 66\% in $\mathrm{HC}$ emissions comparing conventional exhaust pipe with fabricated exhaust pipe with $20 \%$ activated carbon with baffles. There is a reduction in $\mathrm{CO}$ emissions up to 55\% comparing conventional exhaust pipe with fabricated exhaust pipe with $20 \%$ activated carbon with baffles. However from the graphs it is evident that the two way catalytic converter is still superior method for reducing both $\mathrm{HC}$ and $\mathrm{CO}$ emissions effectively. It can also be suggested that various other chemical compounds which can reduce $\mathrm{HC}$ and $\mathrm{CO}$ can be used by this method and it can become another method to reduce emissions in a cost effective manner.

\section{References}

[1]. Smog — Who Does It Hurt? What You Need to Know About Ozone and Your Health (EPA-452/K-99-001)" (PDF). United States Environmental Protection Agency. July 1999

[2]. Monil Shah, Chirag Mistry, Naresh Shimpi, Emission Norms (Case Study) International Journal of Science and Research (IJSR) ISSN (Online): 2319-7064

[3]. Gurwinder Singh, Shubham Parmar \& Dr.Radhey Sham, Effects of EGR and other technologies to reduce emissions in IC engines A Review Imperial journal of interdisciplinary research(IJIR)

[4]. Aluminium silicate - Wikipedia, the free encyclopedia, https://en.wikipedia.org/wiki/Aluminium_silicate

[5]. Activated carbon - Wikipedia, the free encyclopedia, https://en.wikipedia.org/wiki/Activated carbon

[6]. Sodium silicate - Wikipedia, the free encyclopedia, https://en.wikipedia.org/wiki/Sodium_silicate

[7]. Pavan Kumar, Dr. Rajagopal, Dr. Hiregoudar Yerrana Gowda, Raghuram G, Fabrication of Emission Control Silencer for 2-stroke petrol engine using refractory and activated carbon layer. http://www.ijset.in/wp-content/uploads/2015/09/10.2348.ijset 09151157.pdf

[8]. Mayank Hardikar, Amendment in two wheeler silencer International Journal of Science Management \& Engineering Research (IJSMER), Volume 01, Issue 01,Feb-2016.

[9]. Rahul Krishnaji Bawane, Nilima Baliram Gadge, Dinesh Krishnaji Bawane, Reduction of CO \& HC emission of gasoline engine with charcoal-oil silencer. International Journal of Engineering Sciences \& Research Technology.

[10]. Thakur Mukesh, Saikhedjar N.K, Reduction of pollutant emission from two wheeler automobiles using nano-particle as catalyst. Research journal of engineering sciences. Vol.1(3),32-37,Sept (2012) 